\title{
HUBUNGAN PENGETAHUAN ANAK DENGAN KARIES GIGI ANAK KELAS VA SDI RADEN PAKU SURABAYA TAHUN 2020.
}

\author{
Josinta Elsiana Maryanti Tameon \\ Email : josintatameon@gmail.com
}

\begin{abstract}
Frequent oral and dental diseases in Indonesia are tooth caries and high in number. Elementary school age (SD) is one of the children's age groups that are susceptible to tooth caries. A child's knowledge of dental caries is so important that it can increase the degree of dental health and the mouth of tooth caries. The purpose of this study is to identify the relationship of a child's knowledge with child's gear caries and data collection techniques using the knowledge questionnaire and the knowledge karies observation sheet and the data analysis techniques using the chi square test. The study employed a quantitative method with a design for cross sectional. This research sample is an elementary class of VA SDI Raden Paku Surabaya is 52 children. Research shows that the child's knowledge of teeth and mouth karies is largely in the good category of answering 15-22 questions of 35 children (67.2\%), the most teeth karies of teeth are found at criteria $>1$ are in a bad category with 39 children's dental caries (75\%), and thus it appears that there is no link between a child's knowledge and a child's dental caries which are proved by significant value $(0.942 \mathrm{sig}>$ 0.05). In conclusion, a child's knowledge of good tooth karies does not affect the tooth karies of a child.
\end{abstract}

Keyword : Caries teeth, Knowledge, Students

Abstrak: Penyakit gigi dan mulut yang sering dijumpai di Indonesia adalah karies gigi dan jumlahnya cukup tinggi. Usia sekolah Dasar (SD) merupakan salah satu kelompok usia anak yang rentan terhadap karies gigi. Pengetahuan anak tentang karies gigi sangat penting sehingga dapat meningkatkan derajat kesehatan gigi dan mulut dari karies gigi. Tujuan penelitian ini adalah untuk mengidentifikasi hubungan pengetahuan anak dengan karies gigi anak dan teknik pengumpulan data menggunakan kuesioner pengetahuan dan lembar observasi karies gigi anak serta teknik analisis data menggunakan uji chi square. Penelitian ini menggunakan metode kuantitatif dengan desain cross sectional. Sampel penelitian ini adalah anak SD kelas VA SDI Raden Paku Surabaya yang berjumlah 52 anak. Hasil penelitian menunjukkan bahwa pengetahuan anak tentang karies gigi dan mulut sebagian besar pada kategori baik yaitu dapat menjawab $15-22$ pertanyaan sebanyak 35 anak $(67,2 \%)$, angka karies gigi terbanyak terdapat pada kriteria $>1$ termasuk dalam kategori buruk dengan karies gigi sebanyak 39 anak (75\%), sehingga disimpulkan bahwa tidak ada hubungan antara pengetahuan anak dengan karies gigi anak yang dibuktikan dengan nilai signifikasi $(0,942 \mathrm{sig}>$ $0,05)$. Kesimpulannya pengetahuan anak tentang karies gigi yang baik tidak mempengaruhi karies gigi anak.

Kata Kunci: Karies gigi; Pengetahuan; Anak sekolah.

Copyright (C) 2021 Jurnal Skala Kesehatan. Politeknik Kesehatan Banjarmasin All rights reserved

Corresponding Author:

Josinta Elsiana Maryanti Tameon

E-mail: josintatameon@gmail.com 


\section{PENDAHULUAN}

Kesehatan gigi dan mulut merupakan keadaan sehat dari jaringan keras dan jaringan lunak gigi serta berbagai unsur yang berhubungan dalam rongga mulut, yang memungkinkan individu makan, berbicara dan berinteraksi sosial tanpa mengalami disfungsi, gangguan estetik, dan ketidaknyamanan karena adanya penyakit, penyimpangan oklusi dan kehilangan gigi sehingga mampu hidup produktif secara sosial dan ekonomi (Kemenkes, 2015).

Hasil Riset Kesehatan Dasar (Riskesdas) tahun 2018, proporsi masalah kesehatan gigi dan mulut sebesar $57,6 \%$, terjadi peningkatan dibandingkan (Riskesdas) Jawa Timur tahun 2018 sebesar 54,22\%. Hal ini menunjakan tidak ada perbedaan signifikan penyakit gigi dan mulut di Indonesia pada umumnya dengan propinsi jawa timur khususnya.

Masalah penyakit gigi dan mulut yang paling banyak dijumpai di Indonesia adalah karies gigi. Karies gigi adalah suatu penyakit jaringan keras gigi yang disebabkan oleh mikroorganisme pada karbohidrat yang ada pada permukaan gigi yang dapat difermentasi sehingga terbentuknya asam dan terjadi demineralisasi pada jaringan keras gigi, ditandai kerusakan jaringan keras gigi pada permukaan gigi meluas kebagian lebih dalam dari gigi tersebut (Gayatri dan Mardianto, 2016).

Menurut Sondang dan Mahada (2008) dalam Gayatri dan Mardianto (2016), faktor utama peyebab terjadinya karies gigi adalah host, mikroorganisme, substrat dan waktu. Faktor pendukung yang mempengaruhi terjadinya keparahan karies antara lain pengalaman karies, sosial ekonomi, usia, jenis kelamin, pengetahuan dan pendidikan, letak geografis dan perilaku terhadap kesehatan gigi dan mulut.

Menurut Blum (1974) dalam Notoatmodjo (2012), faktor yang mempengaruhi kesehatan dipengaruhi oleh 4 faktor utama yakni lingkungan, perilaku, pelayanan kesehatan dan keturunan atau hereditas. Anak - anak usia SD merupakan salah satu kelompok usia yang rentan terhadap karies gigi. Karies pada anak usia sekolah perlu mendapat perhatian yang lebih besar karena umumnya kurang mengetahui pemeliharaan kebersihan gigi dan mulutnya sendiri. Anak pada umumnya senang makan dan minum yang manis serta jarang membersihkannya, sehingga gigi geliginya banyak mengalami karies atau gigi berlubang (Gayatri dan Mardianto, 2016).

Anak yang telah terbentuk memori, sikap dan kebiasaan perilaku, kebiasaan merawat gigi dan mulut, maka perilaku hidup ini akan terbawa sampai dewasa. Pengetahuan tentang cara hidup bersih dan sehat, termasuk pemeliharaan kesehatan gigi perlu ditanamkan oleh orang tua kepada anak. Orang tua harus memiliki pengetahuan, pendidikan, sosial ekonomi serta perilaku yang baik sehingga dapat menjadi contoh bagi anak dalam berperilaku menjaga kebersihan gigi dan mulut, agar gigi geligi pada anak usia sekolah dapat bebas dari karies gigi (Kemenkes, 2015).

Pengetahuan merupakan hasil dari tahu yang terjadi setelah seseorang melakukan pengindraan tehadap suatu objek tertentu. Proses pengindraan tersebut terjadi melalui pancaindra manusia yakni indra pengelihatan, pendengaran, penciuman, rasa dan raba. Sebagian besar pengetahuan yang diperoleh manusia melalui indra pengelihatan dan indra pendengaran. Pengetahuan merupakan domain yang sangat penting dalam membentuk tindakan seseorang (Notoatmodjo, 2012).

Program UKGS adalah pelaksanaan pelayanan asuhan kesehatan gigi dan mulut pada anak yaitu meliputi penyuluhan, pemeriksaan gigi dan mulut, kegiatan preventif dan kuratif terbatas (Kemenkes, 2015). Kegiatan UKGS yang dilakukan oleh Puskesmas dan Tenaga kesehatan mempunyai indikator, standar atau target pelayanan kesehatan gigi dan mulut. Menurut standar Nasional dan WHO yang ditetapkan sejak tahun 2010 adalah anak Indonesia usia 12 tahun $\mathrm{DMF}-\mathrm{T}=<1$ yang berarti setiap anak Indonesia yang berusia 12 tahun yang berkaries maksimal 1 gigi ( Permenkes, 2015).

Program UKGS di laksanakan dalam rangka pelaksanaan pelayanan asuhan kesehatan 
gigi dan mulut di sekolah terdiri dari beberapa kegiatan yaitu, 1) melakukan penjaringan atau pemeriksaan gigi dan mulut anak sekolah, 2) melakukan penyuluhan tentang kesehatan gigi dan mulut yakni lubang gigi dan menyikat gigi, 3) Melaksanakan kegiatan sikat gigi bersama, 4) Melakukan rujukan masalah kesehatan gigi dan mulut ke Puskesmas melalui guru UKS.

Berdasarkan data penjaringan kesehatan gigi dan mulut yang dilakukan terhadap anak kelas VA SDI Raden Paku Surabaya berjumlah 25 anak sekolah yang dilakukan pemeriksaan diperoleh data anak dengan karies gigi sebanyak 63 elemen gigi dari 18 anaksedangkan data yang tidak berkaries sebanyak 7 orang anak. dengan hasil data DMF-T rata - rata $63 / 25=$ 2,52 anak kelas VA SDI Raden Paku Surabaya DMF-T =>1 yang artinya tidak sesuai dengan indikator nasional berdasarkan data DMF-T adanya kesenjangan antara kenyataan dengan indicator standar Nasional dan target jangka panjang 2020 maka masalah penelitian ini adalah tingginya rata - rata karies gigi pada anak kelas VA SDI Raden Paku Surabaya tahun 2020.

Tujuan umum dari penelitian ini adalah diketahuinya hubungan pengetahuan anak dengan karies gigi anak kelas VA SDI Raden Paku Surabaya tahun 2020. Tujuan khusus penelitian ini adalah 1) Mengidentifikasi tingkat pengetahuan anak dengan karies gigi. 2) Mengidentifikasi angka karies gigi. 3) Menganalisis hubungan pengetahuan anak dengan karies gigi anak kelas VA SDI Raden Paku Surabaya tahun 2020.

\section{BAHAN DAN METODE}

Penelitian ini merupakan penelitian analitik dengan desain cross sectional dimana cara pengambilan data variabel bebas dan variabel terikat dilakukan sekali waktu pada saat yang bersamaan. Penelitian ini menganalisis hubungan variabel bebas (pengetahuan anak) terhadap variabel terikat ( karies gigi anak kelas VA SDI Raden Paku Surabaya). Populasi dalam penelitian ini adalah anak kelas VA SDI Raden Paku Surabaya yang berjumlah 52 anak. Sampel penelitian ini menggunakan total sampling sebanyak jumlah populasi yakni 52 anak. Pengumpulan data pada variabel bebas yaitu pengetahuan anak tentang karies gigi menggunakan lembar kuesioner. Pengumpulan data pada variabel terikat yaitu karies gigi anak dilakukan pemeriksaan permukaan gigi dengan cara observasi dan inspeksi menggunakan alat diagnostic set (sonde, kaca mulut, kapas dan alcohol) serta lembar pemeriksaan gigi. Analisis data yang dilakukan pada penelitian ini adalah 1) Analisis data pengetahuan anak tentang karies gigi dalam bentuk rata - rata. 2) Analisis karies gigi anak kelas VA SDI Raden Paku Surabaya dalam bentuk rata -rata. 3) Analisis data hubungan pengetahuan anak kelas VA SDI Raden Paku Surabaya tentang karies gigi anak menggunakan uji chi square.

\section{HASIL DAN PEMBAHASAN}

Berdasarkan penelitian yang dilakukan, maka diperoleh hasil sebagai berikut :

Tabel 1. Distribusi Frekuensi Jawaban Pengetahuan Anak Tentang Gejala Karies Gigi Anak Kelas VA SDI Raden Paku Surabya Tahun 2020

\begin{tabular}{|c|c|c|c|c|c|}
\hline \multirow[t]{3}{*}{ NO } & \multirow[t]{3}{*}{ PERNYATAAN } & \multicolumn{4}{|c|}{ SKOR } \\
\hline & & \multicolumn{2}{|c|}{ BENAR } & \multicolumn{2}{|c|}{ SALAH } \\
\hline & & $\boldsymbol{\Sigma}$ & $\%$ & $\Sigma$ & $\%$ \\
\hline 1 & Tanda awal terjadinya lubang gigi. & 38 & 73 & 14 & 30 \\
\hline 2 & $\begin{array}{l}\text { Yang sering dirasakan jika lubang pada gigi } \\
\text { dibiarkan semakin dalam. }\end{array}$ & 38 & 71 & 15 & 29 \\
\hline 3 & $\begin{array}{l}\text { Yang terjadi bila lubang pada gigi sudah } \\
\text { parah. }\end{array}$ & 38 & 71 & 15 & 29 \\
\hline
\end{tabular}




\begin{tabular}{cccc}
\hline Total & 114 & 44 & 145 \\
\hline Rata-rata & \multicolumn{4}{c}{76,6} & 29,3 \\
\hline Kategori & Baik & \\
\hline
\end{tabular}

Berdasarkan tabel 1 diketahui bahwa rata - rata pengetahuan anak tentang gejala karies gigi anak kelas VA SDI Raden Paku Surabaya pada tahun 2020 sebesar 71,6\% termasuk kategori baik.

Tabel 2. Distribusi Frekuensi Jawaban Pengetahuan Anak Tentang Penyebab Karies Gigi anak kelas VA SDI Raden Paku Surabaya Tahun 2020.

\begin{tabular}{|c|c|c|c|c|c|}
\hline \multirow[t]{3}{*}{ NO } & \multirow[t]{3}{*}{ PERNYATAAN } & \multicolumn{4}{|c|}{ SKOR } \\
\hline & & \multicolumn{2}{|c|}{ BENAR } & \multicolumn{2}{|c|}{ SALAH } \\
\hline & & $\boldsymbol{\Sigma}$ & $\%$ & $\boldsymbol{\Sigma}$ & $\%$ \\
\hline 1 & $\begin{array}{l}\text { Jenis makan dan minum yang dapat } \\
\text { menyebabkan lubang gigi. }\end{array}$ & 40 & 77 & 12 & 33 \\
\hline 2 & $\begin{array}{l}\text { Jajanan yang dapat merusak gigi pada anak } \\
\text { - anak. }\end{array}$ & 45 & 86 & 7 & 24 \\
\hline 3 & $\begin{array}{l}\text { Makanan yang sebaiknya dihindari untuk } \\
\text { kesehatan gigi. }\end{array}$ & 42 & 81 & 10 & 19 \\
\hline 4 & $\begin{array}{l}\text { Posisi gigi yang dapat menyebabkan gigi } \\
\text { berlubang. }\end{array}$ & 28 & 54 & 24 & 46 \\
\hline & Total & 155 & & 53 & \\
\hline & Rata-rata & & 74,5 & & 30,5 \\
\hline & Kategori & & & & \\
\hline
\end{tabular}

Berdasarkan tabel 2 diketahui bahwa rata - rata pengetahuan anak tentang penyebab karies gigi anak kelas VA SDI Raden Paku Surabaya tahun 2020 sebesar 74,5\% dan termasuk kategori baik. Pengetahuan anak tentang penyebab karies gigi anak kelas VA SDI Raden Paku Surabaya tahun 2020 yang terendah pada pernyataan posisi gigi yang dapat menyebabkan gigi berlubang yaitu $54 \%$ termasuk kategori kurang.

Tabel 3 Distribusi Frekuensi Jawaban Pengetahuan Anak Tentang Akibat Karies Gigi Anak Kelas VA SDI Raden Paku Surabaya Tahun 2020.

\begin{tabular}{|c|c|c|c|c|c|}
\hline \multirow[t]{3}{*}{ NO } & \multirow[t]{3}{*}{ PERNYATAAN } & \multicolumn{4}{|c|}{ SKOR } \\
\hline & & \multicolumn{2}{|c|}{ BENAR } & \multicolumn{2}{|c|}{ SALAH } \\
\hline & & $\boldsymbol{\Sigma}$ & $\%$ & $\boldsymbol{\Sigma}$ & $\%$ \\
\hline 1 & $\begin{array}{l}\text { Akibat jika anak mengalami lubang gigi yang } \\
\text { tidak dirawat. }\end{array}$ & 37 & 71 & 15 & 29 \\
\hline 2 & $\begin{array}{l}\text { Yang terjadi jika anak mengalami lubang gigi } \\
\text { dan berwarna hitam pada bagian depan. }\end{array}$ & 36 & 69 & 16 & 31 \\
\hline 3 & Akibat jika gigi anak banyak yang berlubang. & 39 & 75 & 13 & 25 \\
\hline 4 & $\begin{array}{l}\text { Akibat anak dengan keadaan gigi berlubang } \\
\text { yang parah. }\end{array}$ & 39 & 75 & 13 & 25 \\
\hline & Total & 151 & & 57 & \\
\hline
\end{tabular}




\begin{tabular}{ccc} 
Rata-rata & 72,5 & 27,5 \\
\hline Kategori & Baik & \\
\hline
\end{tabular}

Berdasarkan tabel 3 diketahui bahwa rata - rata pengetahuan Anak tentang akibat karies gigi anak kelas VA SDI Raden Paku Surabaya tahun 2020 sebesar 72,5\% termasuk kategori baik. Pengetahuan tentang anak tentang akibat karies gigi anak kelas VA SDI Raden Paku Surabaya tahun 2020 yang terendah pada pernyataan yang terjadi jika anak mengalami lubang gigi dan berwarna hitam pada bagian depan yaitu $69 \%$ termasuk kategori cukup.

Tabel 4. Distribusi Frekuensi Jawaban Pengetahuan Anak Tentang Cara Pencegahan Karies Gigi Anak Kelas VA SDI Raden Paku Surabaya Tahun 2020.

\begin{tabular}{|c|c|c|c|c|c|}
\hline \multirow[t]{3}{*}{ NO } & \multirow[t]{3}{*}{ PERNYATAAN } & \multicolumn{4}{|c|}{ SKOR } \\
\hline & & \multicolumn{2}{|c|}{ BENAR } & \multicolumn{2}{|c|}{ SALAH } \\
\hline & & $\boldsymbol{\Sigma}$ & $\%$ & $\boldsymbol{\Sigma}$ & $\%$ \\
\hline 1 & Minimal lama waktu menyikat gigi yang tepat. & 37 & 71 & 15 & 29 \\
\hline 2 & Minimal menyikat gigi dalam sehari. & 45 & 86 & 7 & 14 \\
\hline 3 & $\begin{array}{l}\text { Bahan yang digunakan untuk menyikat gigi } \\
\text { yang baik. }\end{array}$ & 43 & 82 & 9 & 18 \\
\hline 4 & Alat yang digunakan untuk menyikat gigi & 43 & 82 & 9 & 18 \\
\hline 5 & Waktu menyikat gigi yang tepat. & 39 & 75 & 13 & 25 \\
\hline 6 & $\begin{array}{l}\text { Waktu yang tepat untuk memeriksa gigi anak di } \\
\text { puskesmas }\end{array}$ & 35 & 67 & 17 & 33 \\
\hline & Total & 242 & & 70 & \\
\hline & Rata-rata & & 77 & & 23 \\
\hline
\end{tabular}

Berdasarkan tabel 4 diketahui bahwa rata - rata pengetahuan Anak tentang cara pencegahan karies gigi pada anak kelas VA SDI Raden paku Surabaya tahun 2020 sebesar 77,\% dan termasuk dalam kategori baik. Pengetahuan anak tentang cara pencegahan karies gigi anak kelas VA SDI Raden Paku Surabaya tahun 2020 yang terendah pada pernyataan yaitu 67\% termasuk kategori cukup.

Tabel 5. Distribusi Frekuensi Jawaban Pengetahuan Anak Tentang Cara Penanganan Karies Gigi Anak Kelas VA SDI Raden Paku SurabayaTahun 2020.

\begin{tabular}{clccccc}
\hline \multirow{2}{*}{ NO } & \multicolumn{1}{c}{ PERNYATAAN } & \multicolumn{5}{c}{ SKOR } \\
\cline { 3 - 6 } & & \multicolumn{3}{c}{ BENAR } & \multicolumn{1}{c}{ SALAH } \\
\cline { 3 - 6 } & & $\boldsymbol{\Sigma}$ & $\%$ & $\boldsymbol{\Sigma}$ & $\%$ \\
\hline $\mathbf{1}$ & $\begin{array}{l}\text { Yang dilakukan jika gigi sudah terlihat } \\
\text { berlubang, namun masih kecil. }\end{array}$ & 33 & 63 & 19 & 37 \\
\hline $\mathbf{2}$ & $\begin{array}{l}\text { Yang dilakukan bila terlihat lubang pada } \\
\text { permukaan gigi, namun tidak sakit }\end{array}$ & 31 & 60 & 21 & 40 \\
\hline 3 & $\begin{array}{l}\text { Yang dilakukan bila terdapat lubang pada } \\
\text { permukaan gigi dan terasa linu. }\end{array}$ & 39 & 75 & 13 & 25 \\
\hline
\end{tabular}




\begin{tabular}{clrrrr}
\hline 4 & $\begin{array}{l}\text { Yang dilakukan bila terdapat lubang pada } \\
\text { permukaan gigi dan terasa linu. }\end{array}$ & 40 & 77 & 12 & 23 \\
\hline $5 \quad \begin{array}{l}\text { Tempat yang tepat untuk memeriksa dan } \\
\text { merawat jika gigi berlubang. }\end{array}$ & 39 & 75 & 13 & 25 \\
\hline Total & 182 & 78 & \\
\hline Rata-rata & & 70 & 30 \\
\hline Kategori & Baik & \\
\hline
\end{tabular}

Berdasarkan tabel 5 diketahui bahwa rata - rata pengetahuan anak tentang cara penanganan karies gigi anak kelas VA SDI Raden Paku Surabaya tahun 2020 sebesar 70\% dan termasuk dalam kategori baik. Pengetahuan tentang anak tentang cara penanganan karies gigi anak kelas VA SDI Raden Paku Surabaya tahun 2020 yang terendah pada pernyataan yang dilakukan bila lubang pada gigi, namun tidak sakit yaitu $60 \%$ dengan kategori kurang.

Tabel 6. Frekuensi Pengetahuan anak Tentang Karies Gigi Anak Kelas VA SDI Raden Paku Surabaya Tahun 2020.

\begin{tabular}{cccc}
\hline No & Kategori & Frekuensi & Persentase \\
\hline $\mathbf{1}$ & Pengetahuan Baik & 35 & 67,2 \\
\hline $\mathbf{2}$ & Pengetahuan Cukup & 7 & 13,4 \\
\hline $\mathbf{3}$ & Pengetahuan kurang & 10 & 19,2 \\
\hline & TOTAL & 52 & 100 \\
\hline
\end{tabular}

Dari tabel 6 diatas, diketahui frekuensi rata - rata pengetahuan anak tentang karies gigi anak kelas VA SDI Raden Paku Surabaya tahun 2020 termasuk kategori baik

Tabel 7 Frekuensi Karies Gigi Pada Anak Kelas VA SDI Raden Paku Surabaya tahun 2020

\begin{tabular}{cccc}
\hline No & Kategori & Frekuensi & Persentase \\
\hline $\mathbf{1}$ & $\leq 1$ Gigi & 13 & 25 \\
\hline $\mathbf{2}$ & $>1$ Gigi & 39 & 75 \\
\hline & TOTAL & 52 & 100
\end{tabular}

Dari tabel 7 diatas, diketahui rata - rata karies gigi pada anak kelas VA SDI Raden Paku Surabaya tahun 2020 dengan kategori buruk sebesar (75\%).

\section{Analisis Data Dan Pengujian Hipotesis}

Analisis data untuk mengetahui hubungan pengetahuan anak dengan karies gigi anak kelas VA SDI Raden Paku Surabaya dalam penelitian ini dilakukan dengan uji hipotesis menggunakan chi square dengan hasil sebagai berikut :

Tabel 8. Hubungan Pengetahuan Anak dengan Karies Gigi Anak Kelas VA SDI Raden Paku Surabaya tahun 2020.

\begin{tabular}{|c|c|c|c|c|}
\hline \multirow{2}{*}{$\begin{array}{c}\text { Pengetahuan } \\
\text { Anak }\end{array}$} & \multicolumn{2}{|c|}{ Karies Gigi } & \multirow[t]{2}{*}{ Jumlah } & $\boldsymbol{P}$ \\
\hline & $\begin{array}{l}\text { DMF-T } \\
=<1\end{array}$ & $\begin{array}{l}\text { DMF-T } \\
>1\end{array}$ & & value \\
\hline
\end{tabular}




\begin{tabular}{cccccccc}
\hline & $\Sigma$ & $\%$ & $\Sigma$ & $\%$ & $\mathrm{~N}$ & $\%$ & \\
\cline { 1 - 6 } Baik & 1 & 21,1 & 2 & 46,1 & 3 & 67,2 & \\
& 1 & & 4 & & 5 & & \\
\cline { 1 - 5 } Cukup & 2 & 3,8 & 5 & 9,6 & 7 & 13,4 & \\
\hline Kurang & 1 & 1,9 & 9 & 17,3 & 1 & 19,2 & 0,942 \\
& 1 & 25 & 3 & 75 & 5 & 100 & \\
Total & 5 & & 9 & & 2 & & \\
& & & & & & &
\end{tabular}

Berdasarkan tabel 8 di atas, menunjukan bahwa rata - rata anak dengan karies gigi lebih tinggi pada anak dengan pengetahuan kategori baik daripada anak dengan pengetahuan kategori buruk. Rata - Rata anak dengan karies pada anak dengan pengetahuan kategori buruk lebih tinggi daripada anak dengan pengetahuan kategori baik.

Pada penelitian ini data tidak memenuhi syarat dilakukan uji chi square karena terdapat 2 cell $(33,3 \%)$ dengan expected count $<5$, maka penelitian ini menggunakan uji altrnative menggunakan kolomogorow smirnov dan diketahui nilai $P$ value yaitu 0,942 .

Berdasarkan nilai uji pada kolom asymp sig. (2-tailed) 0,942 > 0,05 maka H0 diterima dan $\mathrm{H} 1$ ditolak yang artinya tidak ada hubungan pengetahuan anak dengan karies gigi anak kelas VA SDI Raden Paku Surabaya tahun 2020.

\section{PEMBAHASAN}

\section{Pengetahuan anak tentang karies gigi}

Secara umum tingkat pengetahuan anak tentang karies gigi anak kelas VA SDI Raden Paku Surabaya tahun 2020 termasuk kategori baik tapi berdasarkan hasil jawaban, pengetahuan anak pada pernyataan yang dapat menyebabkan potensi atau resiko yang besar terjadinya karies gigi termasuk dalam kategori buruk, artinya masih banyak anak yang belum mengetahui secara lengkap tentang karies gigi anak yaitu gejala, penyebab, akibat, cara pencegahan dan cara penanganan karies gigi anak.

Berdasarkan analisis data pada tabel 1 tentang gejala karies gigi anak terdapat hasil jawaban dalam kategori baik yaitu yang terjadi bila lubang pada gigi sudah parah. Menurut pendapat Tarigan (2016), mengemukakan bahwa gejala yang timbul bila lubang gigi sudah parah jika dibiarkan akan timbul nanah akibat peradangan yang terjadi pada gusi dan jaringan otot. Seharusnya bila lubang gigi pada anak yang sudah parah harus di lakukan pengobatan agar tidak timbul nanah yang dapat merusak jaringan disekitar gigi. Orangtua beranggapan bahwa lubang gigi pada anak yang sudah parah merupakan hal yang biasa terjadi pada anak anak sehingga tidak perlu dilakukan pemeriksaan maupun pengobatan karena nantinya akan diganti dengan gigi yang baru.

Berdasarkan analisis data pada tabel 2 tentang penyebab karies gigi anak terdapat hasil jawaban dalam kategori kurang yaitu posisi gigi yang dapat menyebabkan gigi berlubang. Menurut pendapat Savitri (2014), menyatakan bahwa gigi bertumpuk / crowding merupakan keadaan yang dapat menimbulkan gangguan pada penampilan, pengunyahan dan saat membersihkan gigi. Keadaan gigi crowding dapat memudahkan terjadinya karies gigi. Seharusnya posisi gigi yang bertumpuk / crowding pada anak perlu dilakukan perawatan karena merupakan salah satu penyebab terjadinya karies gigi karena posisi gigi yang bertumpuk susah untuk dibersihkan dari sisa -sisa makanan sehingga rentan terjadinya karies. Orangtua 
perpandangan bahwa gigi crowding merupakan keadaan yang sudah ditakdirkan sehingga tidak perlu dilakukan perawatan. Selain membutuhkan biaya yang besar ketersediaan tenaga dokter, peralatan dan bahan juga cukup sulit.

Berdasarkan analisis data pada tabel 3 tentang akibat karies gigi anak terdapat hasil jawaban dengan kategori cukup yaitu yang terjadi jika anak mengalami lubang gigi dan berwarna hitam pada bagian depan. Menurut Tampubolon (2006) dalam Dewanti (2012), mengemukakan bahwa seseorang yang mengalami masalah kesehatan gigi khususnya karies gigi akan mengalami ketidaknyamanan psikis seperti tidur terganggu, sulit berkonsetrasi dan merasa malu. Seharusnya lubang gigi dan berwarna hitam pada bagian depan menyebab anak merasa malu. Orangtua beranggapan lubang gigi pada bagian depan merupakan hal yang wajar terjadi pada anak - anak pada umumnya sehingga tidak perlu di permasalahkan.

Berdasarkan analisis data pada tabel 4 tentang cara pencegahan karies gigi terdapat hasil jawaban dengan kategori cukup yaitu waktu yang tepat untuk memeriksa gigi ke puskesmas Menurut Kemenkes RI (2012) menyatakan bahwa perilaku menjaga kesehatan gigi dan mulut yaitu dengan rutin ke dokter gigi 6 bulan sekali.Hal ini dilakukan untuk mencegah, mendeteksi, secara dini apabila ada kelainan dan mendapatkan perawatan gigi segera sebelum keadan semakin parah jika gigi bermasalah,jangan lupa untuk menanyakan kepada dokter akibat yang mungkin timbul dari tindakan yang dilakukan oleh dokter gigi hanya ketika merasa sakit gigi karena keterlambatan penanganan dapat menyebabkan penyakit yang lebih serius lagi.

Berdasarkan analisis data pada tabel 5 tentang cara penanganan karies gigi anak terdapat hasil jawaban dengan kategori kurang yaitu yang dilakukan jika gigi sudah terlihat berlubang namun masih kecil. Menurut Arikhman dkk., (2018) menyatakan bahwa seseorang yang terkena penyakit gigi dan mulut khususnya karies gigi perlu mendapat perawatan agar penjalaran penyakit dapat dicegah. Perawatan yang sebaiknya dilakukan adalah penambalan. Seharusnya karies gigi yang masih kecil dilakukan penambalan agar lubang gigi tidak semakin parah. Orangtua beranggapan bahwa lubang gigi yang masih kecil dapat dihilangkan dengan menyikat gigi atau dibiarkan dapat sembuh dengan sendirinya.

Pada penelitian ini pengetahuan anak tentang cara penanganan karies gigi pada pernyataan tempat yang tepat untuk memeriksa dan merawat gigi jika gigi berlubang termasuk kategori baik. Menurut Andayasari (2014), menyatakan bahwa pelayanan yang diberikan di poli gigi antara lain pemeriksaan, penumpatan gigi sulung dan gigi tetap, pengobatan pulpa, pencabutan gigi tetap dan gigi sulung, pembersihan karang gigi. Seharusnya orang tua dapat memeriksa kesehatan gigi dan mulut secara rutin di poli gigi puskesmas. Orangtua beranggapan bahwa memeriksa gigi di puskesmas hanya membuang waktu kerja mereka. Selain itu jarak yang cukup jauh antara puskesmas dan rumah serta biaya transportasi yang tidak sedikit menjadi faktor pendukung untuk membiarkan anak yang terkena karies gigi tidak mendapat perawatan. Orangtua sering mengantar anak mereka untuk dilakukan pemeriksaan gigi apabila sudah dalam keadaan parah dan terasa sakit.

Berdasarkan analisis data hasil jawaban pengetahuan anak tentang gejala, penyebab, akibat, cara pencegahan dan cara penanganan karies gigi dengan kategori buruk dipengaruhi oleh informasi yang didapat anak tentang karies gigi anak kurang lengkap. Pengetahuan yang kurang lengkap tentang karies gigi dapat disebabkan oleh tingkat pendidikan orangtua. Tingkat pendidikan orang tua anak kelas VA SDI Raden Paku Surabaya tahun 2020 yang terbanyak adalah tamatan sekolah menegah pertama (SMP) sehingga tidak dapat memahami informasi yang diperoleh secara baik. Hal ini sesuai dengan penelitian yang dilakukan oleh Purwati dkk., (2017) menyatakan bahwa semakin tinggi tingkat pendidikannya akan semakin mudah menyerap informasi dan inovasi baru termasuk kesehatan gigi. Sebaliknya bila tingkat pendidikan rendah akan sulit memahami atau menyerap informasi yang diterima. 
Pengetahuan anak tentang karies gigi anak dengan kategori baik dapat diperoleh dari berbagai sumber informasi seperti mendengar penyuluhan yang dilakukan petugas kesehatan gigi pada kegiatan posyandu bayi/balita. Selain kegiatan posyandu bayi / balita pengetahuan tentang karies gigi juga diperoleh dengan membaca dari poster pada papan informasi yang disediakan.

Kemungkinan faktor lain, anak dengan pengetahuan tentang karies gigi dengan kategori baik dapat diperoleh dengan membaca dari media informasi. Tingkat kemajuan perkembangan teknologi dan informasi saat ini dapat juga membawa dampak terhadap informasi mengenai kesehatan gigi dan mulut khususnya karies gigi. Informasi tentang karies gigi dapat diperoleh dari mass media seperti siaran televisi, siaran radio serta membaca dari sarana media sosial pada handphone seperti facebook, google, youtube dan lain - lain. Selain itu pengetahuan orangtua dapat diperoleh dari pengalaman semasa kecil sampai sekarang maupun saat mengikuti pendidikan di sekolah. Hal ini sesuai pendapat Notoatmodjo (2012), yang menyatakan bahwa pengetahuan seseorang dapat dipengaruhi oleh beberapa faktor seperti pengalaman, fasilitas, keyakinan, dan pendidikan yang diperoleh selama hidupnya.

Anak yang memiliki tingkat pengetahuan tentang karies gigi yang baik diharapkan dapat mengaplikasikan pengetahuan tersebut dalam sikap, tindakan dan berperilaku sehat dalam pemeliharaan kesehatan gigi dan mulut serta selalu memperhatikan kebersihan gigi dan mulut pada anak. Hal ini sesuai dengan pendapat Afiati dkk., (2017) yang menyatakan bahwa ketika seseorang memiliki pengetahuan yang lebih tinggi maka perhatian akan kesehatan gigi dan mulut akan semakin tinggi. Sebaliknya ketika seseorang memiliki pengetahuan yang kurang maka perhatian akan perawatan gigi juga rendah.

\section{Identifkasi Karies gigi anak kelas VA SDI Raden Paku Surabaya.}

Berdasarkan tabel 7 di atas, hasil identifikasi karies gigi anak kelas VA SDI Raden Paku Surabaya tahun 2020, persentase Kondisi anak dengan karies gigi $>1$ lebih tinggi dari anak dengan karies gigi $\leq 1$.

Kemungkinan penyebab terjadinya karies gigi pada anak kelas VA SDI Raden Paku Surabaya dapat dipengaruhi oleh beberapa faktor baik dari dalam maupun dari luar. Salah satu faktor peyebab terjadinya karies gigi yaitu pengetahuan. Anak - anak usia sekolah dasar belum mendapat pengetahuan yang cukup tentang menjaga kesehatan gigi dan mulut dari orangtua sehingga tidak mengetahui cara menjaga kesehatan gigi salah satunya adalah kebiasaan menggosok gigi. Hal ini sesuai dengan hasil penelitian yang dilakukan oleh Maulida dkk., (2014) yang menyatakan bahwa terdapat hubungan antara kebiasaan menggosok gigi dengan kejadian karies gigi pada anak di SD Aisyiyah Bustanul Atfal Desa Lebaksiu Lor. Menggosok gigi merupakan upaya pencegahan karies gigi karena dengan menggosok gigi dapat membersihan sisa - sisa makanan dan plak yang dapat menyebabkan karies gigi anak. Kurangnya pengetahuan tentang kesehatan gigi dan mulut yang diberikan orang tua kepada anak - anak sehingga mempengaruhi perilaku menggosok gigi. Anak - anak sering meggosok gigi sesuai kemauan dan keinginan mereka sendiri karena tidak di ajarkan, diingatkan dan diawasi oleh orang tua dalam memelihara kesehatan gigi dan mulutnya.

Faktor penyebab lain terjadinya karies gigi yaitu anak - anak lebih sering dan suka mengkonsumsi makanan kariogenik yang dapat merusak gigi seperti permen, roti, biskuit dan lain - lain. Setelah mengkonsumsi makanan kariogenik anak - anak tidak menggosok gigi secara rutin dengan cara yang baik dan benar sehingga mengakibatkan terjadinya karies gigi. Hal ini sesuai dengan hasil penelitian yang dilakukan oleh Sukari (2018), menyatakan bahwa mengkonsumsi makanan kariogenik dapat menyebabkan resiko terjadinya karies gigi. Terlalu 
banyak karbohidrat, baik gula misalnya, kue, permen, susu, makanan dan minuman manis lainnya dapat mengakibatkan pengeroposan gigi.

Karies gigi pada anak - anak dapat juga dipengaruhi oleh sikap dan perilaku tenaga kesehatan dan guru - guru di sekolah yang tidak peduli akan kesehatan gigi anak sekolah dasar. Selain itu, tidak adanya kebijakan - kebijakan dan peraturan yang berwawasan kesehatan gigi baik dari pihak puskesmas dan pihak sekolah sehingga status kesehatan gigi khususnya karies gigi masih tinggi terjadi pada anak sekolah dasar. Hal ini sesuai dengan penelitian yang dilakukan oleh Green (1980) dalam Notoatmodjo (2012), menyatakan bahwa perilaku dalam hidup sehat pada umumnya dan kesehatan gigi dan mulut khususnya karies gigi anak kelas VA SDI Raden Paku Surabaya dipengaruhi oleh beberapa faktor seperti faktor predisposing, faktor pemungkin dan faktor penguat.

Kemungkinan penyebab lain terjadinya karies gigi pada anak adalah ketersediaan sarana dan prasarana pelayanan kesehatan gigi di puskesmas yang kurang memadai seperti peralatan dan bahan - bahan yang dibutuhkan untuk mencegah terjadinya karies gigi sejak dini. Hal ini sesuai dengan penelitian yang dilakukan oleh Blum (1974) cit Notoatmodjo (2012), yang menyatakan status kesehatan seseorang dipengaruhi oleh lingkungan, perilaku, pelayanan kesehatan dan keturunan. Demikian hal tersebut diperkuat dengan hasil penelitian yang dilakukan oleh Salikun (2018), mengemukakan bahwa karies gigi dapat disebabkan beberapa faktor yaitu pengetahuan, praktik / tindakan, sikap, lingkungan, pelayanan kesehatan dan keturunan.

Dari beberapa hasil penelitian tersebut diatas diketahui bahwa kejadian karies gigi pada anak kelas VA SDI Raden Paku Surabaya dapat disebabkan oleh berbagai macam faktor (multifactor), baik dari dalam ( internal) maupun dari luar (eksternal). Faktor - faktor penyebab tersebut saling berhubungan dan kait mengait satu sama lain (kompleks). Agar gigi geligi anak dapat bebas dari karies gigi maka perlu penanganan dan perhatian yang serius secara menyeluruh terhadap faktor - faktor penyebab terjadinya karies gigi tersebut tidak terbatas pada satu atau dua faktor penyebab.

3. Hubungan pengetahuan Anak Dengan Karies Gigi Anak Kelas VA SDI Raden Paku Surabaya Tahun 2020.

Berdasarkan hasil analisis data secara statistik didapatkan hasil bahwa tidak ada hubungan pengetahuan anak dengan karies gigi anak kelas VA SDI Raden Paku Surabaya tahun 2020.

Hasil penelitian ini sesuai dengan hasil penelitian yang dilakukan oleh Almujadi dkk. (2017) yang menyatakan bahwa tidak ada hubungan pengetahuan kesehatan gigi dan mulut dengan jumlah karies gigi anak kelas III-V SD Muhammadyah Sangoan II Godean Yokyakarta. Selain pengetahuan faktor lain yang menyebabkan karies misalnya kebiasaan anak jajan di sekolah,frekuensi makananyang tidak teratur, anak yang mengalami kesulitan menyikat gigi sedangkan orangtua sudah mengajari cara menyikat gigidan juga ada beberapa faktor luar yang berhubungan dengan karies dapat di pengaruh oleh faktor usia, jenis kelamin, perilaku,lingkungan,pengetahuan dan kesadaran serta sikap terhadap kesehatan gigi dan mulut.

Hasil penelitian ini menunjukan bahwa pengetahuan anak kelas VA SDI Raden Paku Surabaya tentang karies gigi pada tahun 2020 dengan kategori baik tapi rata - rata karies gigi pada anak kelas SDI Raden Paku Surabaya tahun 2020 dengan kategori buruk. Hal ini dapat disebabkan oleh beberapa faktor seperti status pekerjaan orang tua yang lebih banyak sebagai wiraswasta sehingga tidak mempunyai waktu yang cukup untuk mendampingi anak dalam memelihara kesehatan gigi khususnya pada saat menggosok gigi. Walaupun orang tua memiliki 
pengetahuan yang baik tapi tidak dapat memdampingi anak - anak untuk memelihara kesehatan gigi dan mulutnya yang baik sehingga menyebabkan terjadinya karies gigi pada anak. Hal ini sesuai dengan penelitian yang dilakukan oleh Noreba dkk., (2015) yang mengemukakan bahwa orangtua yang tidak bekerja memiliki waktu yang lebih banyak bersama anak -anak sehingga lebih memperhatikan kesehatan gigi anaknya daripada orangtua yang bekerja. Orangtua yang bekerja salah satunya sebagai wiraswasta memiliki waktu yang terbatas dalam memperhatikan kesehatan gigi.

Kemungkinan penyebab lain dalam penelitian ini adalah anak dengan pengengetahuan yang baik tetapi anak tidak mengetahui cara menjaga kesehatan gigi dan mulut dengan baik sehingga biasa dapat menyebabkan terjadinya karies gigi pada anak. Tidak semua anak dengan pengetahuan baik dapat menerapkan perilaku kesehatan gigi dalam kehidupan sehari - hari. Hal ini sesuai dengan pendapat Sukari (2018),

Selain pengetahuan anak tentang karies gigi, terdapat faktor - faktor lain yang mempengaruhi karies gigi pada anak yaitu perilaku anak itu sendiri. Orangtua tidak menjadi contoh bagi anak - anak dalam berperilaku kesehatan gigi dengan memelihara kesehatan gigi dan mulut secara baik agar mencegah terjadinya karies gigi. Perilaku anak dalam memelihara dan menjaga kesehatan gigi dan mulutnya ditentukan juga oleh perilaku orangtua serta anggota keluarganya di rumah. Perilaku kesehatan gigi dan mulut orang tua maupun anak anak dapat di pengaruhi oleh faktor lain seperti kebiasaan, adat istiadat dan tradisi pada masyarakat yang menjadi hambatan dalam mengaplikasikan pengetahuan yang dimiliki anak dalam menjaga kesehatan gigi dan mulut sehari - hari. Hal ini sesuai dengan pendapat Blum (1974) cit Notoatmodjo (2012), mengemukakan bahwa faktor - faktor yang dapat mempengaruhi kesehatan seseorang yaitu perilaku, lingkungan, pelayanan kesehatan dan keturunan. Keempat faktor tersebut harus dapat bekerjasama dalam menciptakan status kesehatan yang optimal. Apabila salah satu faktor terganggu maka status kesehatan juga akan terganggu.

Dalam menjaga kesehatan gigi dan mulut anak agar terhindar dari karies gigi anak harus dapat mengaplikasikan pengetahuan yang diperoleh untuk dapat merubah perilaku anak dengan memberikan motivasi,mengontrol kesehatan gigi secara rutin,menciptakan suasana dan sikap yang baik dalam hal kesehatan gigi untuk menunjang terjadinya karies gigi untuk menunjang terjadinya karies gigi anak secara dini.

\section{KESIMPULAN}

Pengetahuan anak dengan karies gigi anak kelas VA SDI Raden Paku Surabaya tahun 2020 termasuk kategori baik dengan kategori karies buruk, sehingga didapati bawha idak ada hubungan pengetahuan anak dengan karies gigi pada anak.

Hasil penelitian ini dapat dijadikan acuan dan bahan evaluasi agar dapat menyampaikan tentang kesehatan gigi dan mulut anak agar terhindar dari karies gigi. Selain itu, dapat menjadi bahan masukan ke pihak sekolah dalam membina kerja sama dengan pihak puskesmas dalam melaksanakan kegiatan - kegiatan untuk meningkatkan kesehatan gigi dan mulut siswa dan siswi SD secara rutin seperti sikat gigi massal,pengadaan kegiatan pelatihan dokter gigi kecil dan mengadakan lomba dengan tema kesehatan gigi dan mulut. Bagi peneliti selanjutnya perlu dilakukan penelitian lanjutan terkait faktor - faktor lain yang dapat mempengaruhi karies gigi pada anak dengan menambah variabel - variabel yang belum diteliti oleh peneliti.

\section{DAFTAR PUSTAKA}

1. Dewanti. Hubungan Tingkat Pengetahuan Tentang Kesehatan Gigi Dengan Perilaku Perawatan Gigi Pada Anak Usia Sekolah di SDN Pondok Cina 4 Depok. Jurnal Kesehatan. 
13 (1). 2012

2. Herijulianti E., Indriani S.T., dan Artini S. "Pendidikan Kesehatan Gigi. ECG. Jakarta. 2012

3. Kemenkes RI. Pedoman Usaha Kesehatan Gigi Sekolah (UKGS). Jakarta. 2012

4. Kemenkes RI. Buku Panduan Pelatihan Kader Kesehatan Gigi Dan Mulut Di Masyarakat. Jakarta. 2012

5. Kemenkes RI. Laporan Nasional Riset Kesehatan Dasar 2013. Jakarta. 2013

6. Kemenkes RI. Peratruan Menteri Kesehatan Republik Indonesia Nomor 75 Tahun 2014 Tentang Puskesmas. Jakarta. 2014

7. Kemenkes RI. Peraturan Menteri Kesehatan Republik Indonesia Nomor 89 Tahun 2015 Tentang Upaya Kesehatan Gigi Dan Mulut. Jakarta. 2015

8. Kemenkes RI. Laporan Nasional Riset Kesehatan Dasar 2018. Jakarta. 2018

9. Mardianto, Gayatri R. W. Gambaran Status Karies Gigi Anak Sekolah Dasar Kota Malang. Jurnal Preventia. 01(1) : 42-50. 2016

10. Notoatmodjo S. Promosi Kesehatan dan Perilaku Kesehatan. Ed. ke-2. Rineka Cipta. Jakarta. 2012

11. Noreba, Restuastuti T., Mammunah F.W. Gambaran Pengetahuan Dan Sikap Orang Tua Siswa Kelas I Dan II SDN 005 Bukit Kapur Dumai Tentang Karies Gigi. Jurnal Jom FK. 02 (2): $01-11.2015$

12. Purwati,D.E. A. "Pengaruh Tingkat Pendidikan Dan Pekerjaan Orang Tua Terhadap Jumlah Karies Gigi Siswa Anak Sekolah Dasar”. Jurnal kesehatan gigi.04 (2): 33-39. 2017

13. Savitri P. I.,Rachmadi P., Widodo. Frekuensi Susunan Gigi Tidak Berjejal Dan Berjejal Rahang Bawah Pada Bentuk Lengkung Narrow Rahang Bawah. Jurnal Kedokteran Gigi. 02 (2) : $130-133.2014$

14. Sugiyono. "Metode Penelitian Kuantitatif”. Alfabeta. Bandung. 2018

15. Sukari, A. "Faktor-Faktor Yang Berhubungan Dengan Kejadian Karies Gigi Pada Murid Sdn.005 Kepenuhan Wilayah Kerja Puskesmas Kepenuhan”. Jurnal Basicedu. 2 (23): 1927. 2018

16. Tarigan R.“Karies gigi”. Ed. ke - 2. ECG. Jakarta. 2016 